\title{
STRUKTUR KOMUNITAS FITOPLANKTON DI PERAIRAN PESISIR PULAU SIANTAN KABUPATEN KEPULAUAN ANAMBAS PROVINSI KEPULAUAN RIAU
}

\section{Phytoplankton Community Structure at Siantan Island Coastal Area Anambas Islands District Riau Islands Province}

\author{
Lani Puspita $^{1 *}$, Notowinarto ${ }^{2}$, Rudi Gunawan ${ }^{3}$ \\ ${ }^{123}$ Program Studi Pendidikan Biologi, FKIP, Universitas Riau Kepulauan, Batam \\ *Koresponden: lanipuspita@mail.com
}

\begin{abstract}
Phytoplankton as a producers and natural food for fish have an important role in aquatic ecosystems, thus indirectly affecting the availability of fish catches. The research was conducted at Siantan Island Coastal Area Anambas Islands District Riau Islands Province. This coastal area is one of the fishing grounds in Anambas Island. This study aims to analyze the community structure of phytoplankton at Siantan Island Coastal Area Anambas Islands District Riau Islands Province. Sampling was conducted during March and April 2012. Community structure parameters analyzed include Species Diversity Level, Species Uniformity Level, and Species Dominance Level. Data were analyzed spatially and temporally. Similarity between the sampling locations was conduted by Multivariate Analysis - Cluster. Results of data analysis showed that the phytoplankton of Bacillariophyceae Class found in the most abundant amount. Diversity Index Value indicates that the level of phytoplankton plankton community in a state of moderate. Species Uniformity Index Value and Species Dominance Index Value indicates that phytoplankton in the three sampling locations are generally in a state of uniform and no one dominates. All three sampling locations have relatively the same condition and between sampling times (morning, afternoon, and evening) are also not very different condition.
\end{abstract}

Keywords: phytoplankton, coastal, Anambas Islands

\section{PENDAHULUAN}

Fitoplankton disebut juga plankton nabati, merupakan organisme mikroskopis yang dapat melakukan fotosintesis seperti halnya tumbuhan dan hidup melayang-layang di perairan. Populasi fitoplankton berjumlah ribuan hingga jutaan sel per liter air laut. Plankton, baik fitoplankton maupun zooplankton, memiliki peranan penting dalam sistem ekosistem perairan di laut sebagai bahan makanan bagi berbagai jenis hewan laut. Fitoplankton merupakan salah satu parameter yang sangat menentukan produktivitas primer di laut, karena fitoplankton mampu berfotosintesis. Hal tersebut membuat fitoplankton dianggap sebagai produsen primer, karena mampu membentuk zat organik dari zat anorganik (Nontji, 2008).

Penelitian ini dilakukan di perairan pesisir Pulau Siantan Kabupaten Kepulauan Anambas Provinsi Kepulauan Riau, tepatnya di perairan Tanjung Momong, Tanjung Lambai, dan Air Asuk. Ketiga perairan tersebut merupakan beberapa daerah tangkapan 
ikan (fishing ground) di Kabupaten Kepulauan Anambas. Fitoplankton sebagai produsen dan pakan alami ikan memiliki peranan penting dalam ekosistem perairan, sehingga secara tidak langsung mempengaruhi keberadaan hasil tangkapan ikan. Penelitian ini bertujuan untuk menganalisis struktur komunitas fitoplankton di Perairan Pulau Siantan Kabupaten Kepulauan Anambas Provinsi Kepulauan Riau.

\section{METODE PENELITIAN}

Penelitian dilaksanakan selama bulan Maret hingga April 2012. Parameter struktur komunitas yang dianalisis meliputi Tingkat Keanekaragaman Jenis, Tingkat Keseragaman Jenis, dan Tingkat Dominansi Jenis. Analisis dilakukan secara spasial (membandingkan struktur komunitas plankton antar lokasi sampling) dan temporal (membandingkan struktur komunitas plankton antar waktu sampling di lokasi yang sama). Selain itu juga dilakukan analisis distribusi fitoplankton secara horizontal (antar statiun sampling di lokasi sampling yang sama). Hasil penelitian ini diharapkan dapat bermanfaat sebagai bahan rujukan bagi berbagai pihak, seperti Dinas Perikanan dan Kelautan serta kelompok nelayan di Kabupaten Kepulauan Anambas.

\section{Lokasi Penelitian}

Penelitian ini dilaksanakan di perairan Pulau Siantan Kabupaten Kepulauan Anambas Provinsi Kepulauan Riau. Pengambilan sampel dilakukan di 3 lokasi sampling, yaitu: perairan Tanjung Lambai, perairan Tanjung Momong, dan perairan Air Asuk. Perairan Tanjung Momong dan Air Asuk merupakan perairan yang berhadapan dengan kawasan hinterlands dan merupakan perairan tertutup; sedangkan perairan Tanjung Lambai merupakan perairan laut lepas (Gambar 1).

Pada perairan Tanjung Lambai dan Tanjung Momong ditetapkan 4 stasiun sampling, yaitu: Stasiun I (50 meter dari tepi pantai), Stasiun II (100 meter dari tepi pantai), Stasiun III (150 meter dari tepi pantai), dan Stasiun IV (200 meter dari tepi pantai). Pada perairan Air Asuk ditetapkan 6 stasiun sampling, yaitu: Stasiun I (50 meter dari tepi pantai), Stasiun II (100 meter dari tepi pantai), Stasiun III (150 meter dari tepi pantai), Stasiun IV (200 meter dari tepi pantai), Stasiun V (250 meter dari tepi pantai), dan Stasiun VI (300 meter dari tepi pantai). 
Pengambilan data dilaksanakan selama 2 minggu, yaitu pada minggu ketiga Maret hingga minggu pertama April 2012. Pada setiap stasiun pengambilan contoh dilakukan 4 kali ulangan hari pengambilan contoh; pada setiap harinya, pengambilan contoh dilakukan dalam 3 waktu, yaitu: pagi hari (antara jam 05.00 sampai 07.00 WIB), sore menjelang malam (antara jam 18.00 sampai 20.00), dan tengah malam (antara jam 23.00 sampai 00.00).

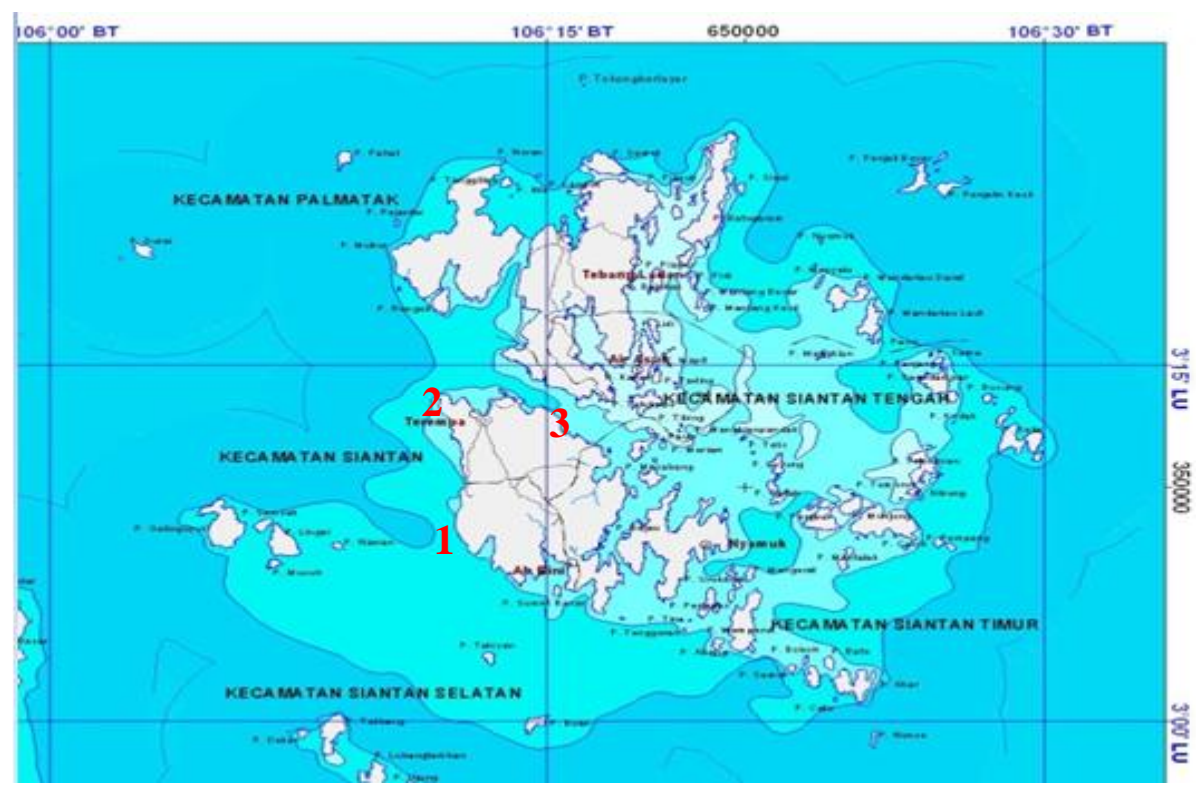

Keterangan: 1. Perairan Tanjung Lambai; 2. Perairan Tanjung Momong; 3. Perairan Air Asuk Sumber: Album Peta Rencana Tata Ruang Wilayah (RTRW) Kab. Kep. Anambas 2011-2031

\section{Alat dan Bahan}

Gambar 1. Peta Lokasi Sampling Fitoplankton

Peralatan yang digunakan dalam penelitian ini adalah: plankton net, gelas ukur volume 1 liter, botol sampel plankton ukuran $10 \mathrm{ml}$, cool box, termometer, perahu motor, mikroskop, pipet tetes, gelas preparat, dan buku identifikasi plankton (Buku "The Illustrations of Marine Plankton of Japan" (Yamaji, 1979)). Dan bahan-bahan yang digunakan dalam penelitian ini adalah: es silica dan larutan lugol 4\%.

\section{Teknik Pengambilan Sampel}

Pengambilan Plankton dapat dilakukan dengan menyaring 10 liter air mengunakan Plankton net. Agar volume air dapat disaring tepat 10 liter digunakan gelas berukuran volume 1 liter. Sampel plankton yang terkumpul pada botol sampel ukuran $10 \mathrm{ml}$ kemudian diawetkan dengan diberi 2 tetes lugol $4 \%$ dan disimpan pada cool box. Sampel 
plankton yang telah diawetkan kemudian dibawa kelaboratorium untuk diidentifikasi jenisnya dan dihitung kelimpahannya.

\section{Metode Identifikasi dan Pencacahan Fitoplankton}

Analisa sampel fitoplankton di laboratorium dilakukan dengan pengamatan di bawah mikroskop. Pengamatan di bawah mikroskop ini dilakukan untuk mengidentifikasi jenis fitoplankton serta mengetahui jumlah individu masing-masing jenis fitoplankton. Dengan mengetahui jenis dan jumlah individu masing-masing jenis, kita kemudian dapat menghitung kelimpahan jenis, keanekaragaman jenis, keseragamanan jenis, dan dominansi jenis.

Pengamatan fitoplankton di bawah mikroskop dilakukan dengan tahapan berikut: (1) mengocok air sampel plankton dalam botol sampel agar homogen, (2) mengambil air sampel dari botol sampel dengan pipet tetes untuk kemudian diteteskan pada preparate glass, (3) mengatur perbesaran mikroskop sehingga morfologi plankton dapat terlihat dengan jelas, (4) membandingkan morfolologi plankton yang teramati di bawah mikroskop dengan buku identifikasi plankton yang dirujuk untuk menentukan jenisnya. Dalam mengidentifikasi plankton digunakan buku panduan "The Illustrations of Marine Plankton of Japan” (Yamaji, 1979).

Pengamatan fitoplankton dan zooplankton dilakukan dengan metode sapuan, yaitu mengamati seluruh fitoplankton yang ada di preparate glass. Perhitungan kelimpahan jenis fitoplankton dengan metode sapuan adalah sebagai berikut:

$$
N_{i}=\frac{n_{i}}{V_{o}} \times \frac{V_{r}}{V_{s}}
$$

$\mathrm{N}_{\mathrm{i}}=$ kelimpahan plankton jenis ke-i (individu/liter)

$\mathrm{n}_{\mathrm{i}} \quad=$ jumlah total individu plankton jenis ke-i yang teramati (individu)

$\mathrm{Vr}=$ volume air contoh hasil saringan dalam botol sampel $(\mathrm{ml})$, yaitu $10 \mathrm{ml}$.

Vo = volume air contoh yang diamati di bawah mikroskop $(\mathrm{ml})$, yaitu volume satu tetes air contoh $(0,05 \mathrm{ml}) \mathrm{x}$ jumlah tetes yang diamati

Vs = volume air yang disaring oleh plankton-net (Iiter), yaitu 20 liter. 


\section{Metode Analisis Data}

Analisis struktur komunitas fitoplankton

$\underline{\text { Keanekaragaman Jenis }}$

Keanekaragaman jenis dihitung dengan menghitung Indeks Keanekaragaman Jenis Shannon - Wienner (H'). Rumusnya adalah sebagai berikut:

$$
H^{\prime}=\sum\left(\frac{N_{i}}{N_{\text {total }}} \bullet \ln \frac{N_{i}}{N_{\text {total }}}\right)
$$

$\mathrm{H}^{\prime} \quad=$ Indeks Keanekaragaman Jenis Shannon - Wienner

$\mathrm{N}_{\mathrm{i}}=$ kelimpahan plankton jenis ke-i (individu/liter)

$\mathrm{N}_{\text {total }}=$ kelimpahan seluruh jenis plankton yang teridentifikasi (individu/liter)

$\ln \quad=$ logaritma natural

Kisaran nilai:

$0 \leq \mathrm{H}^{\prime}<1 \quad$ tingkat keanekaragaman jenis rendah

$1 \leq \mathrm{H}^{\prime}<3 \quad$ tingkat keanekaragaman jenis sedang

$H^{\prime} \geq 3 \quad$ tingkat keanekaragaman jenis tinggi

$\underline{\text { Keseragaman Jenis }}$

Keseragaman jenis dihitung dengan menghitung Indeks Keseragaman Jenis Evenness (E).

Rumusnya adalah sebagai berikut:

$$
E=\frac{H^{\prime}}{\ln S}
$$

$\mathrm{E} \quad=$ Indeks Keseragaman Evenness

$\mathrm{H}^{\prime} \quad=$ Indeks keanekaragaman Shannon - Wienner

$\ln \quad=$ logaritma natural

$\mathrm{S} \quad=$ jumlah species plankton yang ditemukan

Kisaran nilai:

$0 \leq \mathrm{E}<0,3 \quad$ tingkat keseragaman jenis rendah

$0,3 \leq \mathrm{E}<0,6$ tingkat keseragaman jenis sedang

$0,6 \leq \mathrm{E}<1,0$ tingkat keseragaman jenis tinggi

Dominansi Jenis

Dominansi jenis dihitung dengan menghitung Indeks Dominansi Simpson. Rumusnya adalah sebagai berikut: 


$$
D=\sum\left(\frac{N_{i}}{N_{\text {total }}}\right)^{2}
$$

$\mathrm{D}=$ indeks dominansi simpson

$\mathrm{N}_{\mathrm{i}} \quad=$ kelimpahan plankton jenis ke-i (individu/liter)

$\mathrm{N}_{\text {total }}=$ kelimpahan seluruh jenis plankton yang teridentifikasi (individu/liter)

Kisaran nilai:

$0 \leq \mathrm{D}<0,3 \quad$ tingkat dominansi jenis rendah

$0,3 \leq \mathrm{D}<0,6$ tingkat dominansi jenis sedang

$0,6 \leq \mathrm{E}<1,0$ tingkat dominansi jenis tinggi

\section{Analisis Similaritas antar Lokasi Sampling}

Untuk mengetahui tingkat similaritas jumlah jenis fitoplanton diketemukan antar 3 lokasi sampling (perairan Tanjung Lambai, Tanjung Momong, dan Air Asuk), dilakukan Analisis Multivariat - Cluster dengan bantuan software pengolahan data statistik Minitab Versi 14.

\section{HASIL DAN PEMBAHASAN}

\section{Kelimpahan dan Jumlah Jenis Fitoplankton di Perairan Tanjung Lambai, Tanjung} Momong, dan Air Asuk

Pada Gambar 2 disajikan grafik total kelimpahan fitoplankton (individu/liter) dan pada Gambar 3 disajikan grafik jumlah jenis fitoplankton. Pada Gambar 2 dan 3 dapat dilihat bahwa kelimpahan fitoplankton paling tinggi terdapat di Tanjung Momong, namun jumlah jenis fitoplankton paling banyak ditemukan di Air Asuk.

Secara umum tidak terdapat perbedaan kelimpahan dan jumlah jenis fitoplankton secara mencolok antara pagi, sore, dan malam hari. Kelimpahan fitoplankton yang lebih banyak pada Tanjung Momong menunjukkan bahwa lokasi tersebut lebih subur, hal tersebut dimungkinkan dari tipe perairannya yang tertutup sehingga akumulasi nutrien lebih memungkinkan terjadi dan selanjutnya akan dimanfaatkan fitoplankton untuk berfotosintesis dan memperbanyak diri. 


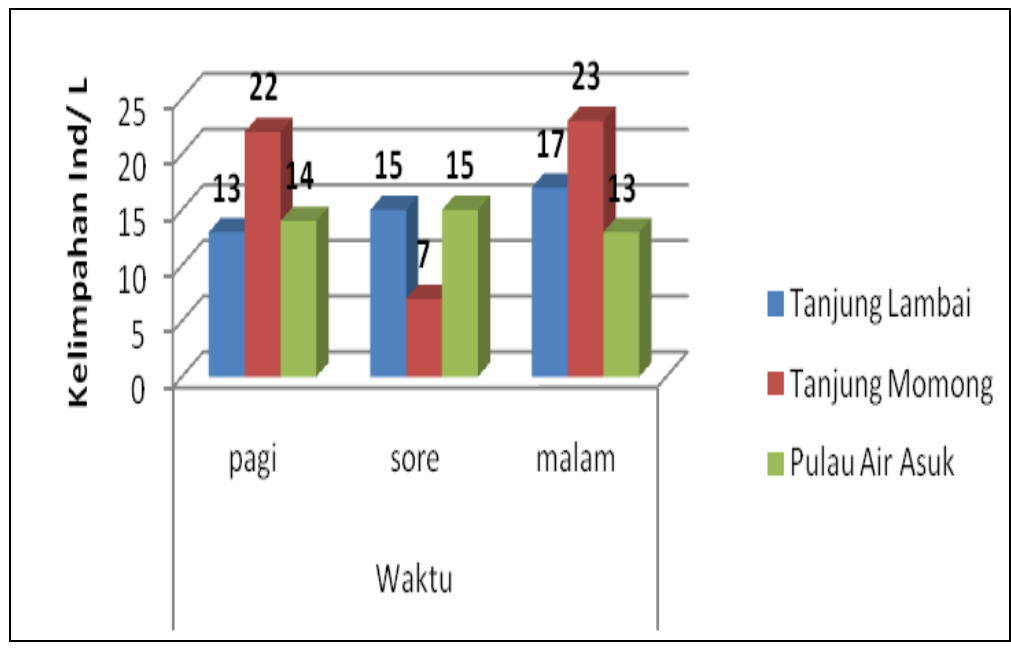

Gambar 2. Total Kelimpahan Fitoplankton (Ind/L) di Masing-Masing Lokasi Sampling pada Pagi, Sore, dan Malam hari

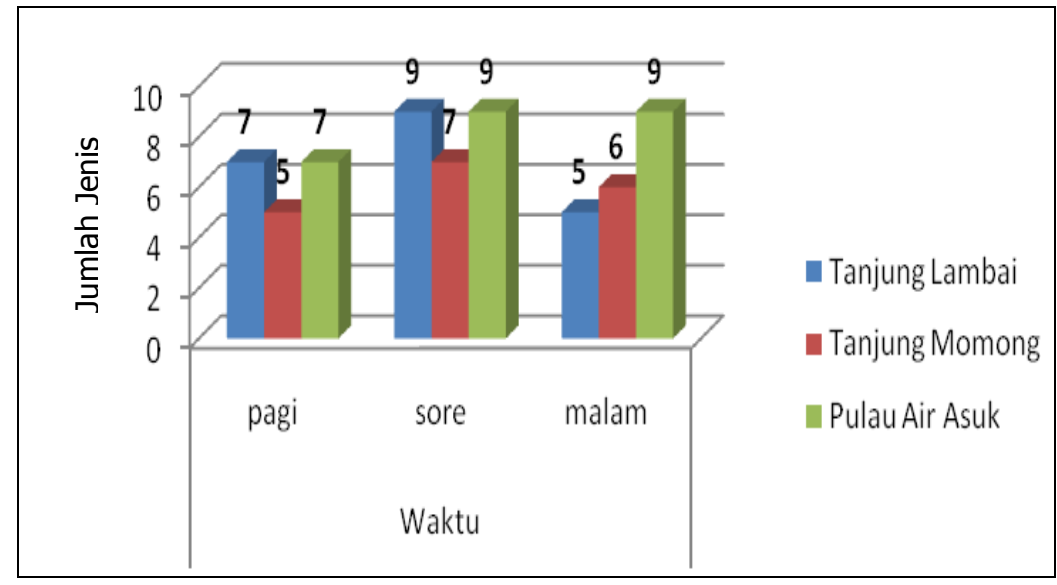

Gambar 3. Jumlah Jenis Fitoplankton di Masing-Masing Lokasi Sampling pada Pagi, Sore, dan Malam hari

Struktur Komunitas Fitoplankton di Perairan Tanjung Lambai, Tanjung Momong, dan Air Asuk

Gambar 4 di bawah memperlihatkan grafik nilai Indeks Keanekaragaman ShannonWiener (H') fitoplankton pada masing-masing lokasi sampling. Pada grafik tersebut dapat dilihat bahwa nilai Indeks H' pada perairan Tanjung Lambai berkisar antara 1,4212 2,000; pada perairan Tanjung Momong berkisar antara 1,0271 - 1,5984; dan pada perairan Air Asuk berkisar antara 1,6003 - 1,9610. Secara keseluruhan dapat dilihat bahwa tingkat keanekaragaman fitoplankton di perairan ini tergolong sedang. Bila suatu perairan memiliki tingkat keanekaragaman jenis "rendah" atau H' berkisar antara 0 sampai 1 , maka komunitas tersebut sedang mengalami ganguan yang biasa disebabkan oleh faktor 
lingkungan (misalnya perairan yang tercemar limbah). Apabila suatu perairan memiliki tingkat keanekaragaman jenis "sedang" atau nilai H' antara 1 sampai 3, maka kondisi komunitas mudah berubah dengan mengalami pengaruh lingkungan relatif kecil. Sedangkan apabila suatu perairan memiliki tingkat keanekaragaman jenis "tinggi" atau nilai H' lebih besar dari 3, maka dapat diketahui bahwa kondisi lingkungan dalam kondisi prima (Odum, 1998 dan Basmi 2000). Dengan kondisi keanekaragaman jenis yang tergolong dalam kategori sedang, maka dapat dikatakan bahwa komunitas fitoplankton di ketiga lokasi ini mudah berubah. Keanekaragaman fitoplankton di ketiga lokasi sampling dapat berubah menjadi rendah apabila ada bahan pencemar masuk, ataupun menjadi tinggi apabila kondisi lingkungannya optimal (terutama kondisi suhu, kecerahan, serta kandungan nitrat dan fosfat sebagai nutrien fitoplankton).

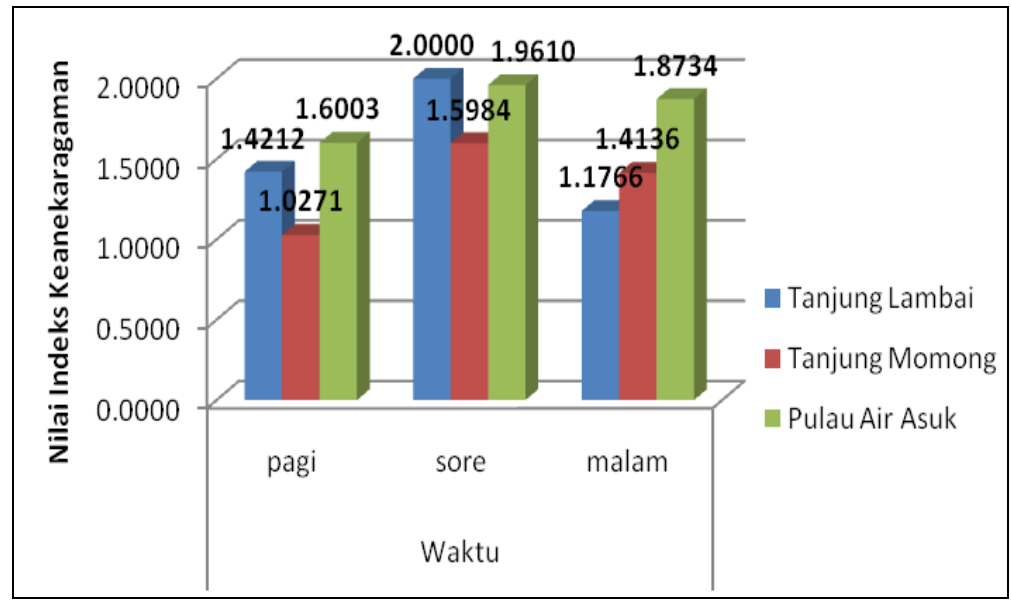

Gambar 4. Nilai Indeks Keanekaragaman Fitoplankton di Masing-Masing Lokasi Sampling pada Pagi, Sore, dan Malam hari

Gambar 5 di bawah menunjukkan grafik nilai Indeks Keseragaman, sedangkan Gambar 6 menunjukkan grafik nilai Indeks Dominansi. Indeks Keseragaman dan Indeks Dominansi menunjukkan nilai yang berbanding terbalik, apabila nilai Indeks Keseragaman tinggi maka nilai Indeks Dominansi rendah dan demikian sebaliknya. Indeks Keseragaman Jenis mengambarkan kondisi habitat relatif serasi (baik) untuk pertumbuhan dan perkembangan masing-masing spesies. Nilai Indeks Keseragaman jenis berkisar antara $0 \leq$ $\mathrm{E}<0,3$ berarti keseragaman antar spesies di dalam komunitas adalah "rendah", mencerminkan keseragaman yang dimiliki masing-masing spesies sangat jauh berbeda. Bila nilai Indeks Keseragaman Jenis berkisar antara $0,3 \leq \mathrm{E}<0,6$ ) berarti keseragaman antar spesies di dalam komunitas "sedang", mencerminkan keseragaman yang dimiliki 
masing-masing tidak jauh berbeda, tidak menunjukkan perbedaan yang sangat mencolok. Bila nilai Indeks Keseragaman Jenis berkisar antara $0,6 \leq \mathrm{E} \leq 1$, maka keseragaman antar spesies dapat dikatakan relatif merata dan hal tersebut menunjukkan kondisi yang baik ( Odum, 1998 dan Basmi 2000).

Bagi Indeks Dominansi, hal yang berlaku adalah kebalikan dari Indeks Keseragaman. Apabila Indeks Dominasi Jenis "rendah" atau nilai berkisar antara ( $0 \leq \mathrm{D}<$ 0,3 , maka di dalam komunitas yang sedang diamati tidak terdapat spesies yang secara ekstrim mendominasi spesies lainnya, hal ini menunjukkan kondisi komunitas dalam keadaan stabil dan kondisi lingkungan prima. Apabila nilai Indeks Dominasi Jenis "sedang" atau nilai indeks berkisar antara $0,3 \leq \mathrm{D}<0,6$, berarti di dalam komunitas tidak ada spesies yang mendominasi secara nyata terhadap spesies lainya. Sedangkan apabila nilai Indeks Dominasi Jenis berkisar antara $0,6 \leq \mathrm{D}<1$, berarti di dalam Komunitas dijumpai spesies yang mendominasi spesies lainya yang mencerminkan kondisi komunitas dalam keadan labil, hal ini menyebabkan habitat yang dihuni sedang mengalami ganguan (Odum, 1998 dan Basmi, 2000).

Pada Gambar 5 dan 6 dapat dilihat bahwa secara keseluruhan nilai Indeks Keseragaman berada pada kisaran 0,6 sampai 1 (keseragaman tergolong tinggi), sedangkan nilai Indeks Dominansi berada pada kisaran umumnya berada pada kisaran $0-0,3$ (keseragaman tergolong rendah); hal ini menunjukkan kondisi lingkungan yang baik. Hal yang sedikit berbeda dijumpai pada perairan Tanjung Momong; di lokasi tersebut, pada pagi dan malam hari dominansi jenis tergolong sedang. Walaupun di perairan Tanjung Momong kondisinya tidak sebaik 2 perairan lainnya, namun nilai indeks tetap menunjukkan bahwa di perairan Tanjung Momong tidak ada spesies yang secara nyata mendominasi spesies lainnya. Apabila dilihat secara temporal, dapat dilihat bahwa antara pagi, sore, dan malam tidak terdapat perbedaan yang nyata antara ketiga waktu sampling tersebut. 


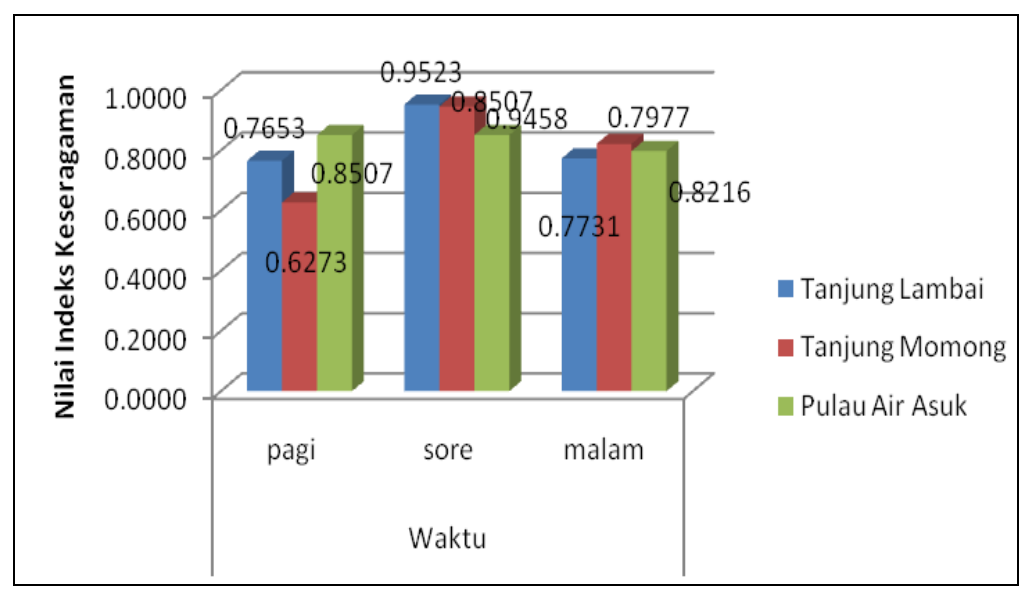

Gambar 5. Nilai Indeks Keseragaman Fitoplankton di Masing-Masing Lokasi Sampling pada Pagi, Sore, dan Malam hari

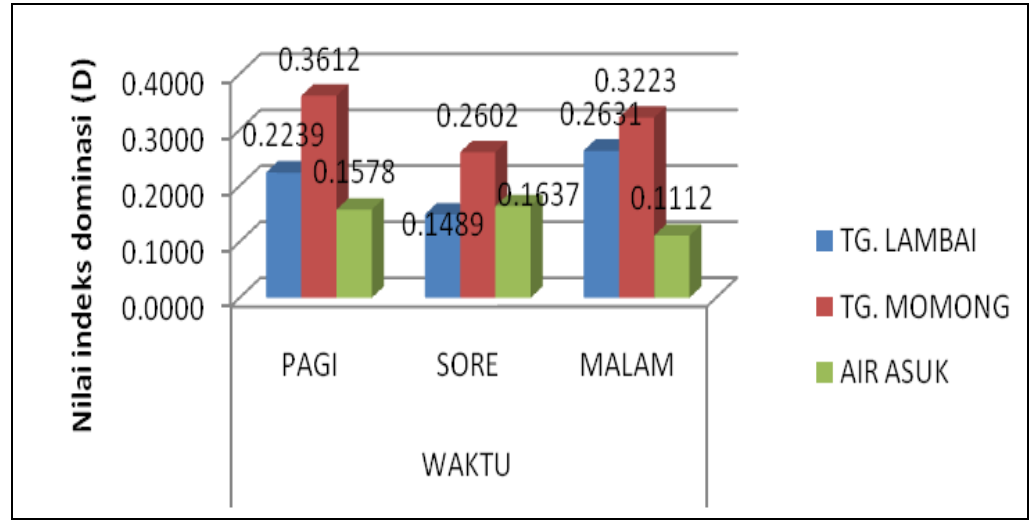

Gambar 6. Nilai Indeks Dominansi Fitoplankton di Masing-Masing Lokasi Sampling pada Pagi, Sore, dan Malam hari

\section{Komposisi Fitoplankton secara Spasial pada Masing-Masing Lokasi Sampling}

Gambar 7 - 9 menyajikan grafik komposisi fitoplankton per kelas di masingmasing lokasi sampling pada setiap stasiunnya. Pada ketiga grafik tersebut dapat dilihat bahwa antar lokasi sampling (Stasiun I sampai VI) tidak menunjukkan trend tertentu (semakin rendah atau semakin tinggi kelimpahan total fitoplanktonnya dengan semakin jauhnya dari tepi pantai). Dari ketiga grafik tersebut dapat dilihat bahwa komposisi fitoplankton di pagi hari lebih beragam dibanding pada sore dan malam hari. Dari kelima kelas fitoplankton yang ditemukan; komposisi fitoplankton paling tinggi yang ditemukan adalah Bacillariophyta. Menurut Nybakken (1992), fitoplankton berukuran besar yang tertangkap oleh jaring plankton terdiri dari dua kelompok besar, yaitu Diatom (Bacillariophyceae) dan Dinoflagellata. Diatom adalah komponen utama dalam komunitas 
plankton, yang mana kehidupan laut tergantung padanya (Nontji, 2008). Mendominasinya jenis-jenis fitoplankton dari kelompok Bacillariophyceae merupakan salah satu tanda baiknya produktivitas perairan.

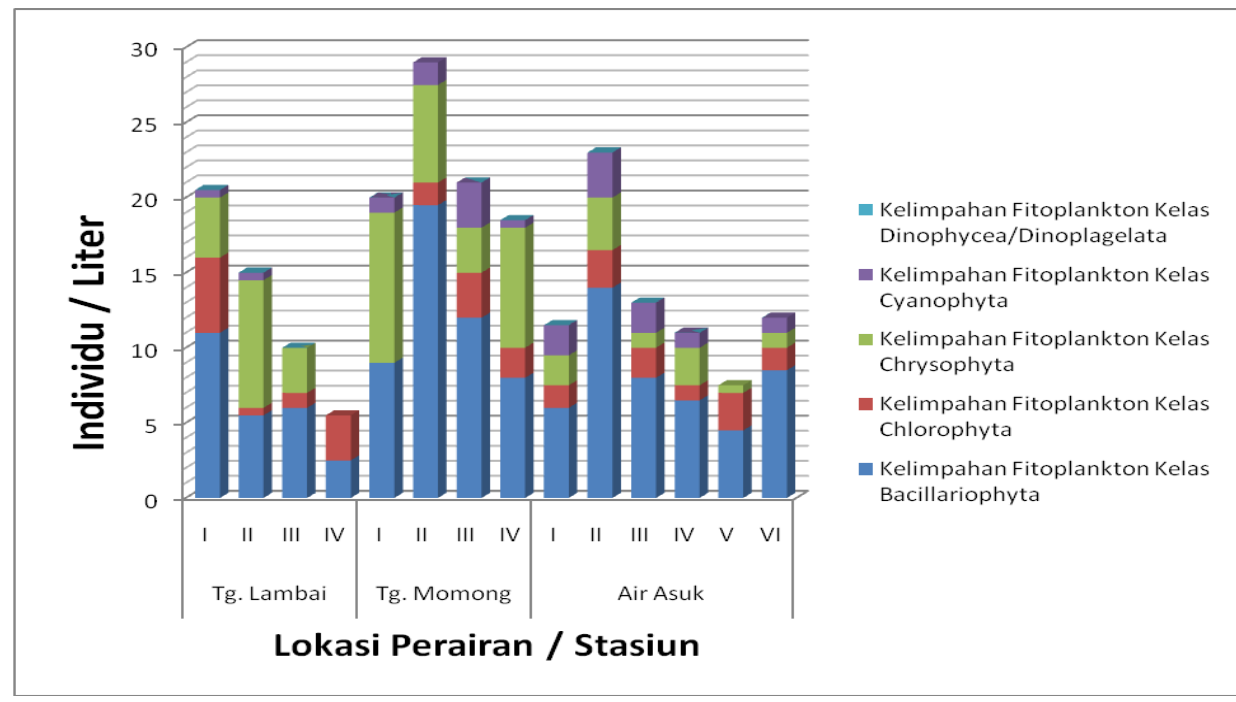

Gambar 7. Komposisi Fitoplankton secara Spasial di Perairan Tanjung Lambai, Tanjung Momong, dan Air Asuk pada Pagi Hari

Di pagi hari, selain Bacillariophyta, kelompok fitoplankton lain yang banyak dijumpai adalah Kelas Chrysophyta. Kondisi yang berbeda dijumpai pada siang hari, yang mana fitoplankton dari Kelas Chlorophyta lebih melimpah daripada Kelas Chrysophyta. Pada malam hari, fitoplankton Bacillariophyta lebih mendominasi dibanding pagi dan sore hari.

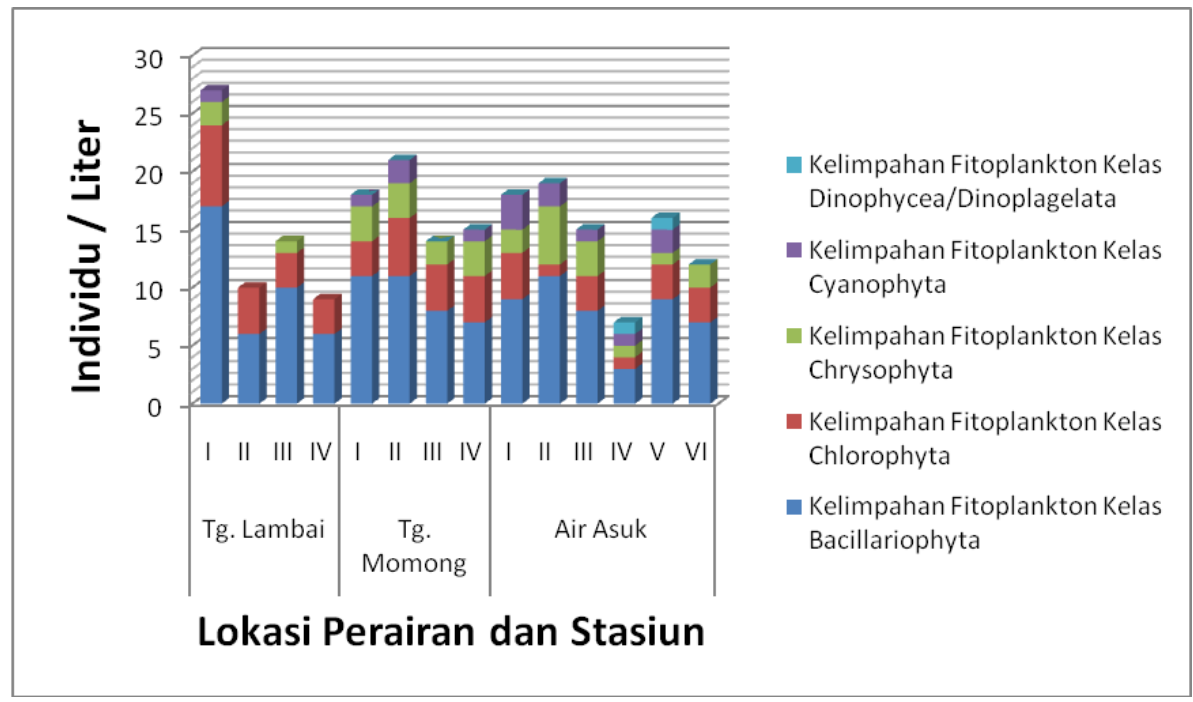

Gambar 8. Komposisi Fitoplankton secara Spasial di Perairan Tanjung Lambai, Tanjung Momong, dan Air Asuk pada Sore Hari 


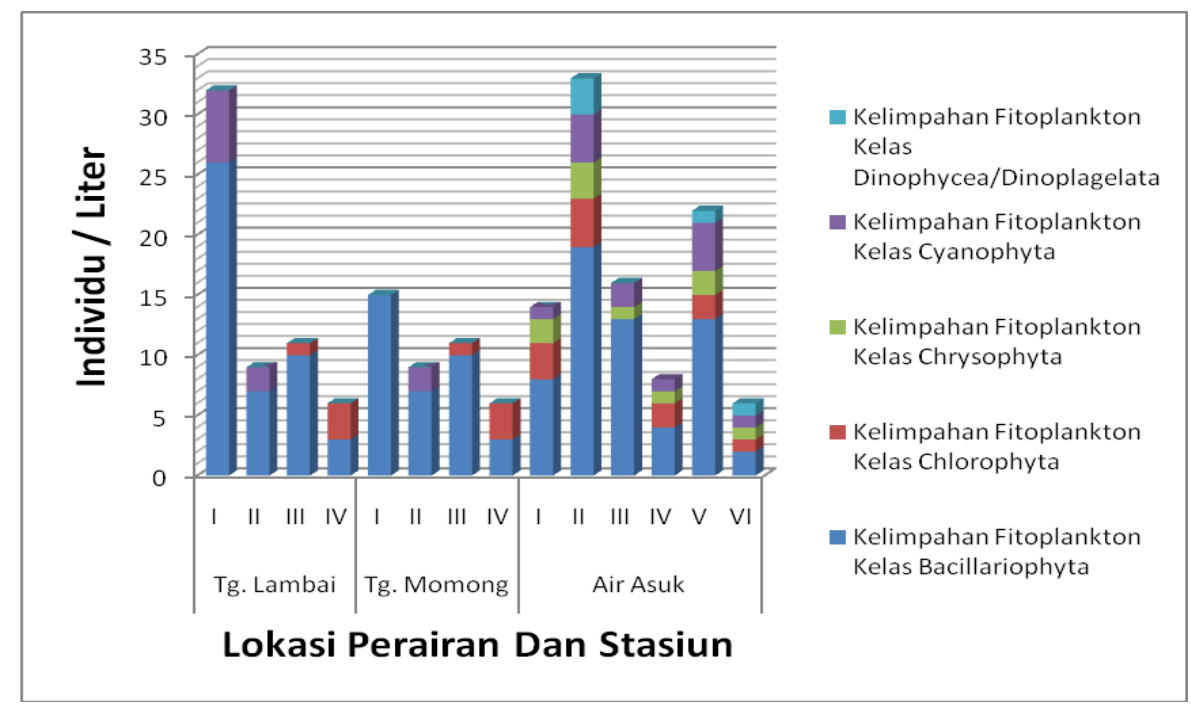

Gambar 9. Komposisi Fitoplankton secara Spasial di Perairan Tanjung Lambai, Tanjung Momong, dan Air Asuk pada Sore Hari

\section{Similaritas Jumlah Jenis Fitoplankton antara Perairan Tanjung Lambai, Tanjung Momong, dan Air Asuk}

Pada Gambar 10 di bawah disajikan dendogram yang menunjukkan tingkat similaritas jumlah jenis fitoplankton antar 3 lokasi sampling. Berdasarkan dendogram tersebut dapat dilihat bahwa ketiga lokasi sampling memiliki tingkat similaritas yang tinggi dalam hal jumlah jenis fitoplankton yang dapat ditemukan (similaritas di atas 99\%). Nilai Similaritas jumlah jenis fitoplankton antara Tanjung Momong dan Tanjung Lambai sebesar 99,58\%, dan similaritas antara ketiga lokasi sampling (Tanjung Momong, Tanjung Lambai, dan Air Asuk) adalah 99,33\%.

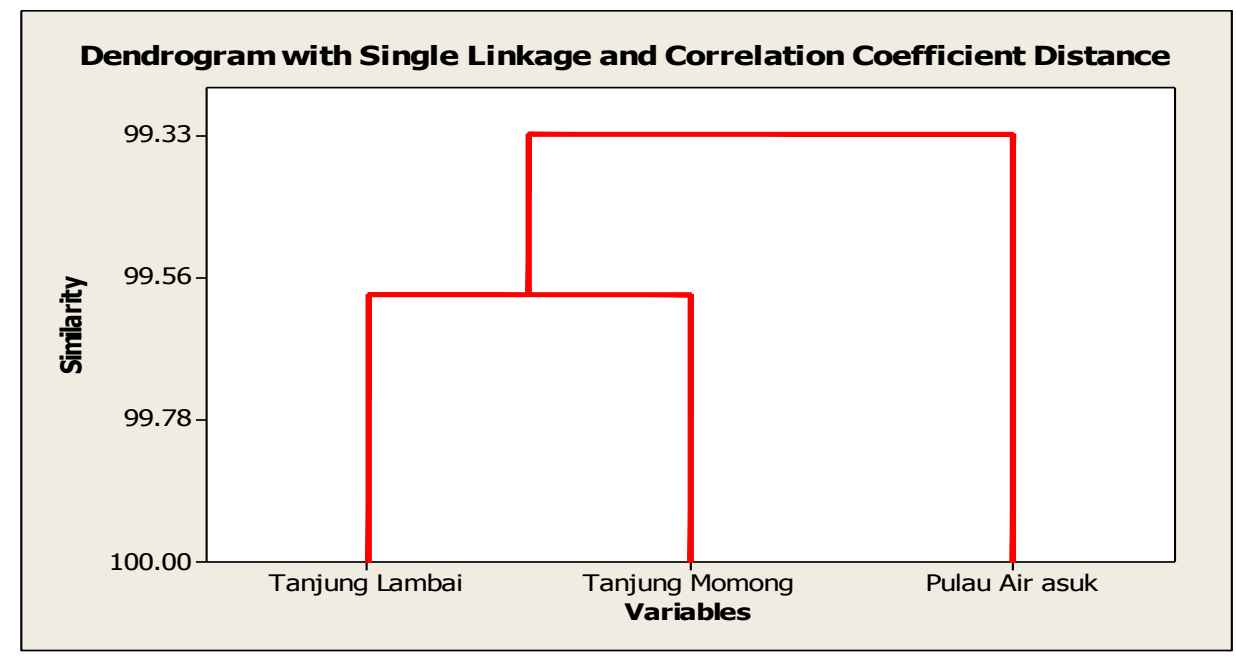

Gambar 10. Dendogram Nilai Similaritas Jumlah Jenis Fitoplankton antara Perairan Tanjung Lambai, Tanjung Momong, dan Pulau Air Asuk 


\section{KESIMPULAN}

Secara keseluruhan dapat disimpulkan bahwa ditinjau dari struktur komunitas planktonnya, kondisi perairan di sekitar Pulau Siantan (perairan Tanjung Momong, Tanjung Lambai, dan Air Asuk) cukup baik, dimana fitoplankton dari kelompok Bacillariophyceae ditemukan dalam jumlah yang cukup melimpah. Nilai Indeks Keanekaragaman Jenis fitoplankton menunjukkan bahwa komunitas plankton berada pada kondisi sedang/moderat yang mudah berubah dengan berubahnya kondisi lingkungan perairan. Walaupun demikian, jumlah individu antar spesies relatif seragam dan tidak ada spesies yang mendominasi.

\section{REFERENSI}

Basmi, J. 2000. Planktonologi: Plankton sebagai Bioindikator Kualitas Perairan. Fakultas Perikanan dan Ilmu Kelautan. Institut Pertanian Bogor. Bogor.

Nontji, A. 2008. Plankton Laut. LIPI Press. Jakarta.

Nybakken, J. W. 1992. Biologi Laut: Suatu Pendekatan Ekologis. PT. Gramedia Pustaka Utama. Jakarta.

Odum, E. P. 1998. Dasar-Dasar Ekologi. Gadjah Mada University Press. Jogjakarta.

Yamaji, I. 1979. Illustrations of the Marine Plankton of Japan. Hoikusha Publishing Co., Ltd. 